\title{
Walking and cycling on shared-use paths: the user perspective
}

Hannah Delaney BA, MSc, PhD

Researcher, Centre for Transport and Society, University of the West of England, Bristol, UK (corresponding author: hannahdelaney_1@hotmail. com; hannah2.delaney@live.uwe.ac.uk)

Graham Parkhurst BA, MSC, DPhil

Professor of Sustainable Mobility, Centre for Transport and Society, University of the West of England, Bristol, UK
Steve Melia MA, PhD, MILT

Senior Lecturer in Transport Planning, Centre for Transport and Society, University of the West of England, Bristol, UK

Shared-use paths are those used by pedestrians and cyclists, either designed for them to mix freely within the space (unsegregated) or with the space allocated to each group by surface markings and signage (segregated). Mobility policy in a number of states is promoting greater use of shared-use paths, but there is only limited knowledge about the user experience, which can be expected to influence patronage. The paper examines experiences of user behaviour and user segregation, drawing on quantitative and qualitative research with pedestrians and cyclists on a heavily used, width-constrained path in Bristol, UK. It has been observed that pedestrians have a modest preference for segregation, while cyclists prefer non-segregation. Both groups exhibited varied, sometimes conflicting perceptions about how users should interact. It is concluded that it will not always be possible to optimise infrastructure design for all users and therefore recommended that the wider context of policy objectives and alternative routes for different user types be considered during design decisions. Whichever approach is taken to segregation, user communities will generally benefit from clear codes of conduct to promote a shared user culture. In the case of unsegregated paths, the separation of flows based on direction, rather than mode, of travel is recommended.

\section{Introduction}

A shared-use path can be defined as a path that is '...designed to accommodate the movement of pedestrians and cyclists. Shared-use routes may be segregated or unsegregated. A segregated route is one where pedestrians and cyclists are separated by a feature such as a white line, a kerb or other feature. On an unsegregated route, pedestrians and cyclists mix freely and share the full width of the route' (DfT, 2012a: p. 5). Many countries with policies to develop more sustainable mobility are promoting the role of off-road walking and cycling facilities such as shared-use paths. However, while many policy and practice documents promote the principle of greater walking and cycling, there is limited international evidence on the effective design of shared-use paths. In the UK, the regulatory guidance such as the Highway Code (DfT, 2015) and Road Traffic Act 1991 give very little reference to the usage of shared-use paths (and so codes of conduct have been introduced for many paths to enhance the walking and cycling environment). This is despite the fact that walkers' and cyclists' willingness to use new facilities will reflect the quality of their experiences. This paper reports on the research undertaken to contribute towards a better understanding of those experiences, specifically on shared-use paths and from the user's perspective. The findings of the research have relevance both for future path design and, through devices such as codes of user conduct, for the management of existing facilities.

The paper first discusses the role of off-road provision for cycling. The need for a clearer code of conduct and a design, which assists users to share off-road space, is then considered. Following this, the methodology of study, which informs this debate, is outlined. The findings relating to shared-use path regulation, segregation and the user experience are then considered, including a discussion on individuals' perceptions of shared-use paths and their users, in the context of promoting effective sharing between users.

\subsection{Importance of off-road provision for cycling}

Expert opinion internationally emphasises the importance of high-quality, off-carriageway provision for cyclists. For example, the CED (2012: p. 53) states that 'cycle track design and maintenance should always be of such a standard that 
cyclists never choose to ride on the carriageway instead'. The important role of off-road paths for both walking and cycling is also highlighted by several authors (Furth, 2012; Gallagher and Parkin, 2014; Pooley et al., 2011), who emphasise that facilities away from the road and motor traffic are a preference for many cyclists as well as pedestrians, and is also a factor in attracting new cyclists and pedestrians.

UK policy towards shared-use path promotion and development, however, is in contradiction with this view: the UK government Department for Transport's (DfT, 2012a) 'Hierarchy of Provision' advises that, when designing for cyclists, the priority should be to improve road conditions and cater for cyclists on the road. Perhaps fortunately, given the counterview, the policy rhetoric is somewhat in contrast to the reality of delivery (Golbuff and Aldred, 2011), with the National Cycle Network (NCN) being largely constituted by off-road provision (Sustrans, 2015a). A similar disparity occurs in respect of usage: it is particular off-road facilities that provide examples of exceptional growth (Melia, 2015). While according to the UK National Travel Survey statistics (DfT, 2014) the percentage of cyclists choosing to cycle on the road has reduced from 46 to $38 \%$ during 2002-2012. There has also been an overall increase in the percentage of people who cycle on cycle paths, off-road lanes and pavements from 25 to $30 \%$ (DfT, 2012b).

Previous studies have identified a significant group of potential cyclists who perceive the conditions for cycling mixed with motor vehicle traffic as too dangerous (Pooley et al., 2011) or whose behaviour shows a strong preference for traffic-free routes (this is particularly true of women: Beecham and Wood, 2013). Therefore, these groups will only begin, return to, or increase cycling if a comprehensive network of safe routes is provided. Such a network will need to rely significantly on off-road routes, which are usually shared with pedestrians. Indeed, half of all trips along the NCN are made by walkers, highlighting that the NCN caters for a mix of cyclists and pedestrians (Sustrans, 2014b).

\subsection{Path regulation and design for effective sharing}

If the aspirations to increase walking and cycling levels are attained this will increase pressure on walking and cycling infrastructure such as shared-use paths, creating tensions between path users. For instance, the comments and discussion threads in response to online blogs, articles and forums relating to user relations on shared-use paths, highlight the unease that can exist between path users (e.g. Davies, 2012; Hembrow, 2014; Lakin, 2015). Of course, there may be differences between perceptions of and actual experiences of conflict. Nonetheless, it is a live issue that can have an impact on how individuals experience shared-use paths.
Along with the potential for conflict between path users, the regulatory framework around the use of shared paths is almost non-existent. The UK Highway Code (DfT, 2015) gives no advice to pedestrians on how to share space with cyclists. There is also very little guidance for cyclists: they are advised to be cautious when passing pedestrians and give adequate space (DfT, 2015). Considering statutes, rather than guidance, cyclists are required to cycle 'carefully' and 'considerately' on shared-use paths (Road Traffic Act 1991) and to keep to the designated side of a segregated path (DfT, 2015), although there is no similar obligation on pedestrians (who may have to cross the cycling side in places). In one publication, the DfT (2012a) guidance appears to establish a further significant principle, in stating that pedestrians usually have the right of way on shared-use paths, yet this is not represented by a clause in the Highway Code (DfT, 2015) or the Road Traffic Act 1991.

To add further detail to and clarify the regulatory framework, some organisations have developed a recommended 'code of conduct' for shared-use paths. The two main codes of conduct in the UK (DfT, 2004; Sustrans, 2013) provide guidance for cyclists only. However, this focus on one user group removes the responsibility for all path users to consider their relations with other users, an expectation that might be considered inherent to the concept of 'shared use'. In specific localities within the UK, there are codes of conduct that refer to both types of path users, such as that for the Two Tunnels route near Bath (Sustrans, 2014c) and for Hailey Park, Cardiff (CC, 2010). However, these are laid out in a way that separates the guidance for cyclists and pedestrians, drawing attention to the different groups of users rather than promoting shared use.

While more effective regulation may enhance user interactions, path design also clearly plays an important role. There are a number of design guidance documents for shared-use paths in the UK (DfT, 2012a; Sustrans, 2014a, 2015b; TfL, 2014). One of the major debates around shared-use path design relates to the decision of whether or not to include segregation between cyclists and pedestrians. In the UK, segregation was previously encouraged as the best option for shared-use paths, as this was believed to be the best way to minimise conflict between path users. However, DfT (2012a: p. 33) now recommends a more sophisticated and bespoke approach whereby designers make 'decisions appropriate to the scheme context rather than adopting certain features as a starting position in the design development process'. The guidance highlights a list of specific factors which should be considered when deciding whether or not to segregate cyclists and pedestrians: 'design objectives, geometry and visibility (sight lines), gradients, available width, frontages along the route, the overall setting, movements across the route, and the volume and composition of different user types' (DfT, 2012a: p. 33). 
Walking and cycling on shared-use paths:

the user perspective

Delaney, Parkhurst and Melia
The current design guidance (DfT, 2012a) was informed by a study (Atkins, 2012) that measured conflict between path users by carrying out quantitative surveys and observing video footage of segregated and non-segregated shared-use paths. Each of the visible and observable interactions between path users were categorised according to a predetermined scale, concluding that there was little difference in the levels of conflict on segregated and non-segregated shared-use paths.

That approach implies that only visible conflict or collisions have a significant impact on user experience. This paper proposes that further investigation into the experiential aspects and personal accounts from path users themselves, including the unobservable and subtle aspects of their journeys, should also be considered when designing and managing shared-use paths. The remainder of this paper reports on the methods and findings of a study of pedestrians' and cyclists' experiences on a shared-use path, with implications for those issues of user regulation and segregated/unsegregated design.

\section{Methodology}

The study aimed to explore the external interactions and the internal experiences of pedestrians and cyclists in a high-frequency context where competition for space already exists. This suggested the need for a two-phased approach focusing on the interactions, the experiences and the relationship between them. The chosen method involved an intercept survey and in-depth interviews using video recordings of respondents' shared path journeys as a discussion tool. The survey comprised fixed-response questions with some opportunities for qualitative commentary; it covered topics including personal journey experiences, interactions, attitudes to other path users, attitudes to sharing the path, regulation of the path, preferences for path improvements. The results of the survey informed the planning of phase II, involving qualitative interviews with path users, recruited from the phase I sample.

\subsection{Case-study site selection}

The research was undertaken with users of a section of the Bristol-Bath Railway Path (BBRP) where it passes through the urban area of Bristol. The BBRP is a $20 \mathrm{~km}$ off-road shareduse path for walking and cycling. It is part of the NCN (Route 4, Sustrans, 2015a). Users travel for a wide variety of utility purposes, as the BBRP is close to schools, residential, shopping and recreational areas, as well as using the route itself for leisure and sport. The city of Bristol and the BBRP have both experienced a recent increase in levels of walking and cycling. From 2001 to 2011 levels of cycling to work in Bristol increased from $4 \cdot 6$ to $7 \cdot 5 \%$ and the levels of walking to work increased from 15.6 to $18 \cdot 4 \%$ (ONS, 2014); all of those rates were considerably higher than the corresponding national averages.

\subsection{Data collection}

The phase I surveys took place in October 2013. The sample frame included all adult users of the BBRP (cyclists and pedestrians) during weekday afternoon peak times (14.00-18.00) and weekend peak times (11.00-16.00). A quota sampling strategy was implemented with three main determining factors: mode, time of day using the path and gender. Path users were requested to stop, using advance-warning and hand-held signs. A total of 400 surveys were completed at the primary survey site and 200 at a secondary survey site. This sample size was deemed appropriate for the time and resources available for this particular project; the sample size also allowed for substantial statistical testing to be carried out during data analysis.

The primary survey site (Figure 1) was typical of the BBRP as a whole; it is a former dual-track railway, a non-segregated,

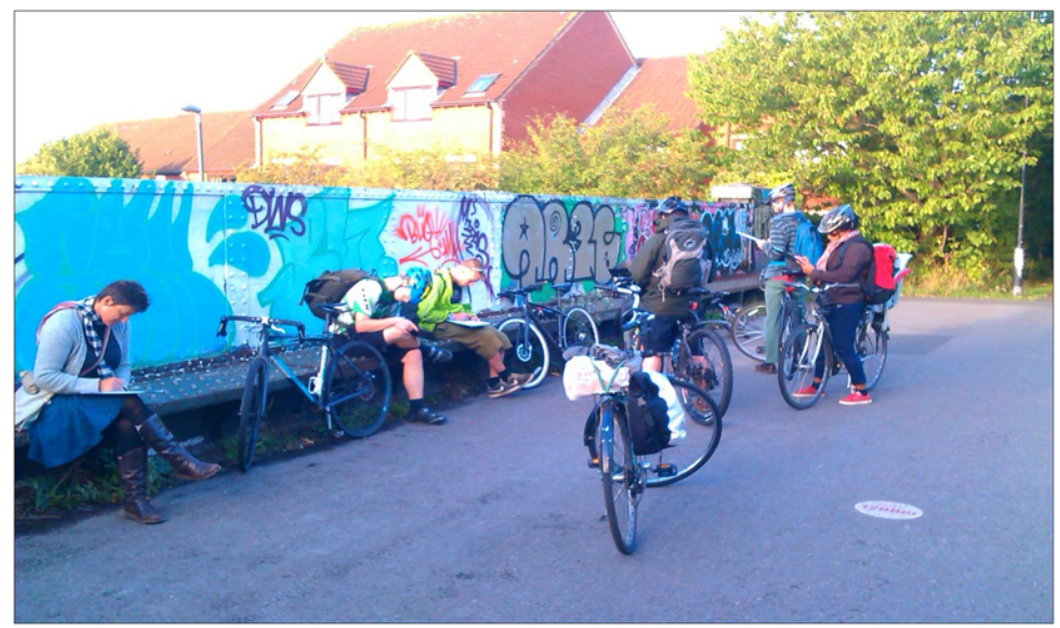

Figure 1. Primary survey site 
shared-use surface, $3 \mathrm{~m}$ wide and laterally constrained. The secondary site (Figure 2) was selected to allow for comparisons between journey experiences and interactions on segregated and non-segregated shared-use paths. Due to the lack of a suitable segregated path section on the BBRP, it was located in Castle Park, central Bristol. Its principal characteristics include purpose built, pedestrian and cyclist segregation, wide pedestrian area and wide cyclist area (about $6 \mathrm{~m}$ ), wide open space adjacent to the cyclists' side of the path.

The phase II interviews took place in September-October 2014; they aimed to gain a more detailed and personal insight into the survey findings. Participants were asked to video record their journeys on the BBRP. The videos were subsequently used within the interviews to reference events and prompt feedback. The minimum required length of journey

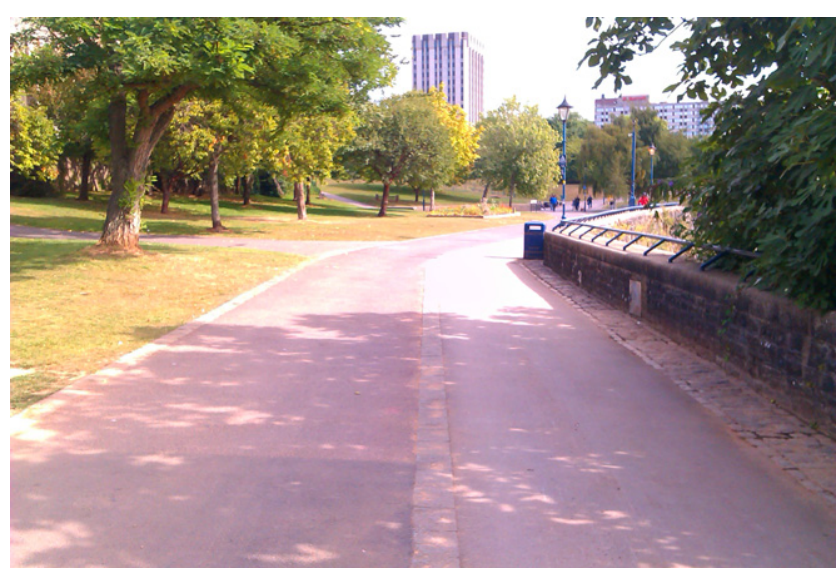

Figure 2. Secondary survey site on the BBRP itself was 10-15 min, to ensure capture of a substantive experience. The researcher met the participants before their journeys to set up a discreet mini camera (on a chest mount for the pedestrians and on the bicycle handlebars for the cyclists). The researcher collected the camera at the end of the journey and arranged a follow-up interview to take place within $48 \mathrm{~h}$ of the recording.

\subsection{Analysis}

The phase I survey data were analysed using exploratory descriptive statistics and chi-square tests of the associations between key variables. The phase II interview data were analysed following Braun and Clark's (2006) '6 Phases of Thematic Analysis', in which the familiarisation phase was carried out by transcribing and rereading the transcripts. As the interviews were transcribed, reference to particular time frames in the corresponding video were also included, allowing the video footage to be easily interpreted and analysed alongside the written transcripts. The data were then coded and further analysed using NVivo software. Each interviewee is identified by a number and a letter: ' $\mathrm{C}$ ' for 'cyclist', ' $\mathrm{P}$ ' for 'pedestrian' and 'B' for 'both'.

\section{Findings relating to shared-use path regulation and segregation}

\subsection{User perspectives on regulation}

When the survey respondents were asked what would make sharing the path with cyclists and pedestrians more enjoyable, the highest percentage of all respondents chose 'a rule that all users should keep to the left' $(60 \cdot 9 \%)$ and 'more formal guidance' $(50 \cdot 1 \%)$; a lower percentage chose 'more measures to reduce speed' $(32 \cdot 8 \%)$ (Figure 3$)$.

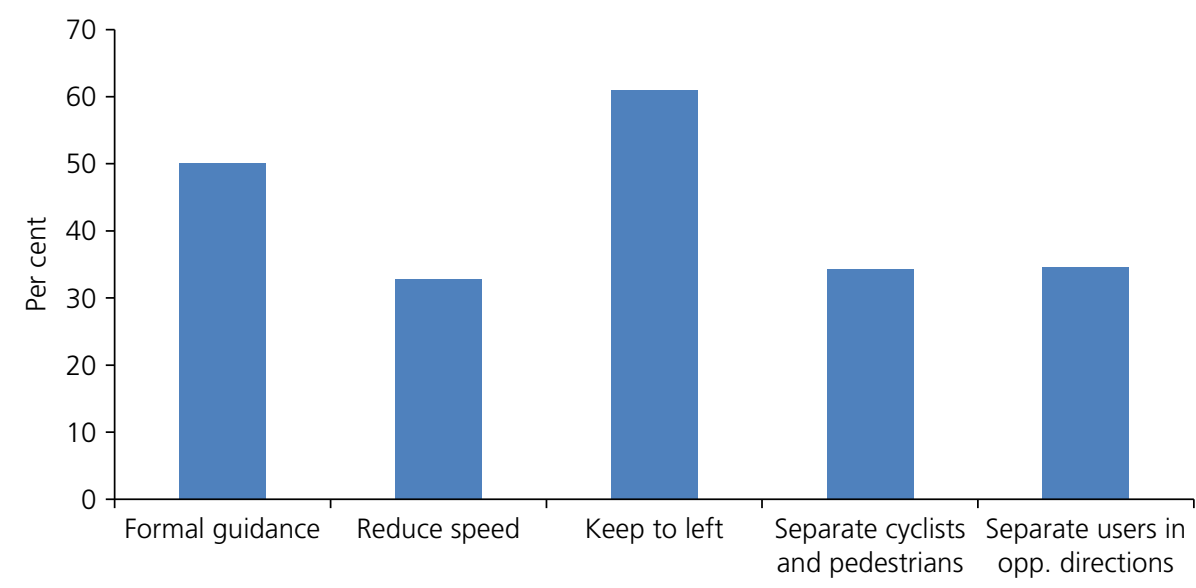

Figure 3. What would make sharing this path more enjoyable? 
The qualitative survey comments provide some further insight into these responses; 'formal guidance' did not necessarily imply support for more regulations. Respondents commented on the importance of encouraging a code of conduct or more guidance/signage on how to use the path. Importantly, others also noted that they would disagree with an increase in formal rules and regulations

\section{More a code of practice than regulation \\ It would be helpful for both if there was guidance on how to appropriate yourself \\ ...but I don't think formal guidance would help matters \\ I prefer having fewer rules - it makes people more conscious of individual encounters}

The variable 'mode' highlighted some differences in the participants' responses. When asked what would make sharing the path more enjoyable, cyclists reported they would like more information on how to share the path. Out of those that chose 'more formal guidance' a higher percentage was cyclists (54.0\%) and out of those that chose 'a rule that all users should keep to the left' a higher percentage was also cyclists (58.4\%). However, the pedestrians wanted to be separated from cyclists and they also wanted the cyclists to slow down for them. Out of those that chose 'measures to reduce speed' a higher percentage of the respondents were pedestrian respondents $(56 \cdot 5 \%)$ and out of those that chose 'white line separation' a higher percentage were also pedestrians $(61 \cdot 3 \%)$. In fact, there is a significant relationship between mode and choosing 'a rule to keep left' ( $p=0.001)$ and between mode and choosing 'segregation between cyclist and pedestrians' ( $p=0 \cdot 001)$ (Figure 4).

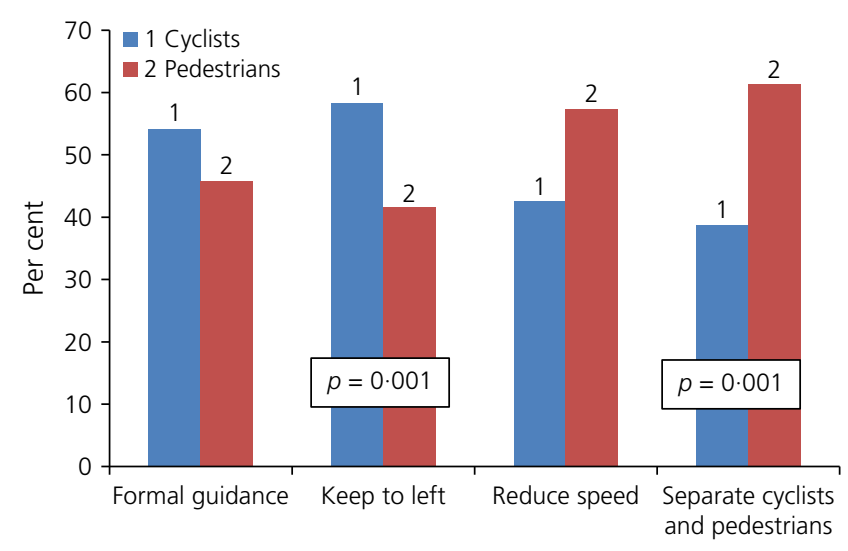

Figure 4. What would make sharing this path more enjoyable? (split by mode)
Further analysis, discussed below, has shown that the pedestrians' preference for segregation was related to their sensory experiences, views on the behaviour of other path users and attitudes to priority of space.

\subsection{User perspectives on segregation}

In terms of sensory experiences, at both segregated and nonsegregated survey sites, a greater percentage of pedestrian respondents reported 'getting lost in their thoughts' than cyclists. On the segregated path, however, there is a significant relationship $(p=0.005)$ between mode and 'getting lost in thoughts' (Figure 5), thus pedestrian respondents appear to pay less attention than cyclists on the segregated path. When considering the behaviour of other path users, a significant relationship was uncovered between how strongly respondents agree/disagree that 'most pedestrians are considerate' and on the path type $(p=0 \cdot 001)$. At the non-segregated survey site $83.7 \%$ of respondents agreed that pedestrians are considerate, whereas a lesser $69 \cdot 9 \%$ of respondents on the segregated survey site agreed that pedestrians are considerate (Figure 6). Thus, segregated path users were less likely to agree that pedestrians are considerate. This may relate to pedestrians frequently walking on the cycling side of the path (Tables 1 and 2).

In relation to experience of frustration, at both survey sites a higher percentage of cyclist users reported being frustrated with another path user than pedestrian users did, although the

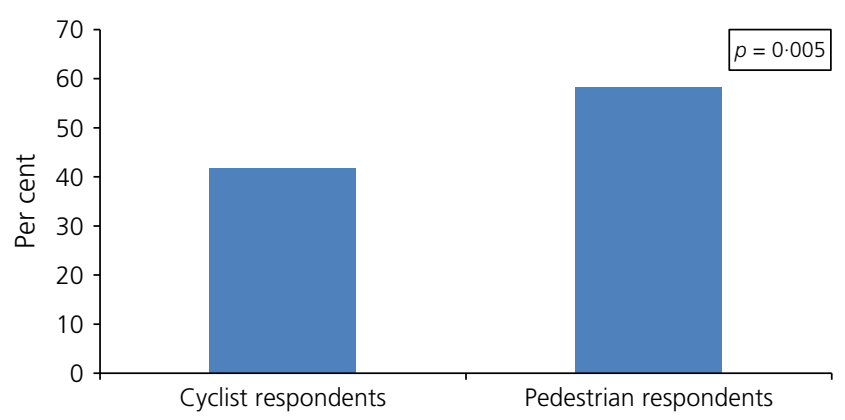

Figure 5. 'I get lost in my thoughts' (segregated survey site)

\begin{tabular}{lccc}
\hline Chi-square test & Chi-square statistic & df & $P$ value \\
\hline Pearson chi-square & 8.062 & 1 & 0.005
\end{tabular}

Table 1. Chi-square test, mode and 'getting lost in thoughts' 


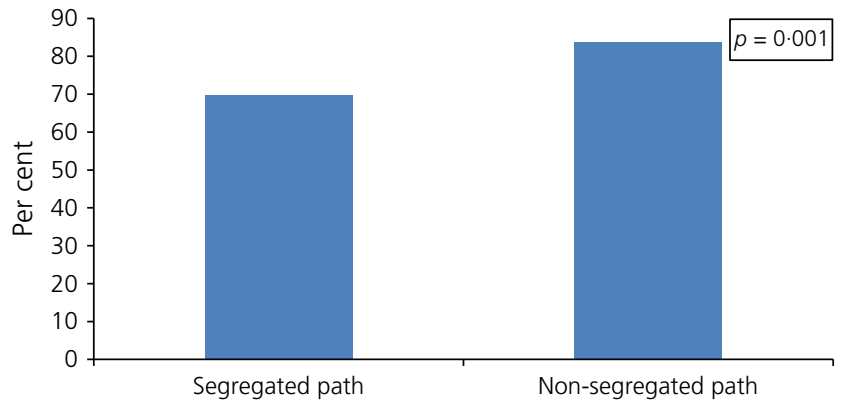

Figure 6. Agree that pedestrians are considerate

\begin{tabular}{lccc}
\hline Chi-square test & Chi-square statistic & df & $P$ value \\
\hline Pearson chi-square & 14.881 & 1 & 0.001
\end{tabular}

Table 2. Chi-square test, path type and consideration of pedestrians

difference was significant $(p=0.003)$ only at the segregated survey site (Figure 7) (Table 3).

Finally, in terms of attitudes to priority on the path, respondents perceived that segregated paths gave more priority to pedestrians and non-segregated paths more priority to cyclists.

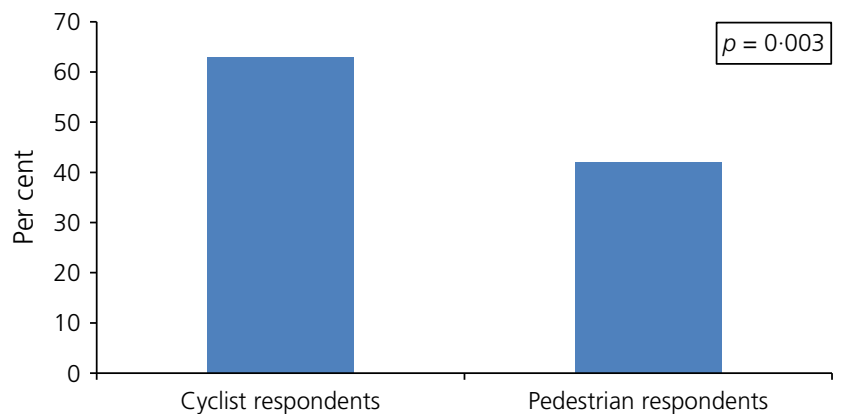

Figure 7. Frustrated with another path user at segregated survey site

\begin{tabular}{lccc}
\hline Chi-square test & Chi-square statistic & df & $P$ value \\
\hline Pearson chi-square & 8.842 & 1 & 0.003
\end{tabular}

Table 3. Chi-square test, mode and experience of frustration (segregated survey site)
On the segregated path, a greater percentage of respondents agreed that pedestrians 'should have priority' compared with the non-segregated path (Figure 8). Moreover, 46.7\% of respondents agreed that cyclists 'do have priority' on the nonsegregated path, whereas only $15.6 \%$ did on the segregated path. However, $12 \cdot 1 \%$ of respondents agreed that pedestrians do have priority on the non-segregated path, whereas $28.6 \%$ did on the segregated path (Figure 9). Thus, it may be concluded that the respondents perceive that segregated paths give more priority to pedestrians and non-segregated paths more priority to cyclists. It appears that pedestrians are more likely to prefer segregated paths; however, the findings suggest that segregation encourages pedestrians to be less aware and less considerate of other path users, resulting in potential cause for frustration among cyclists. The different context of the two paths may also have influenced these responses, however, one runs through a public park, whereas the other was built as a

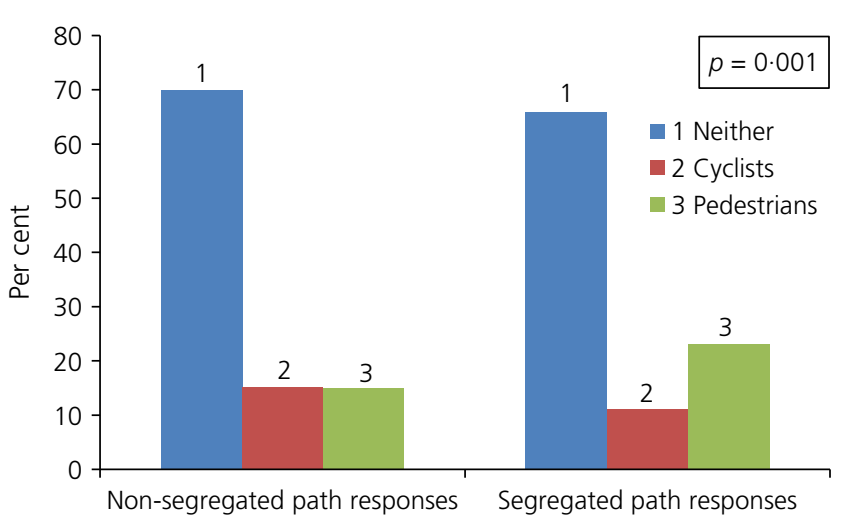

Figure 8. Who should have priority? (split by path type)

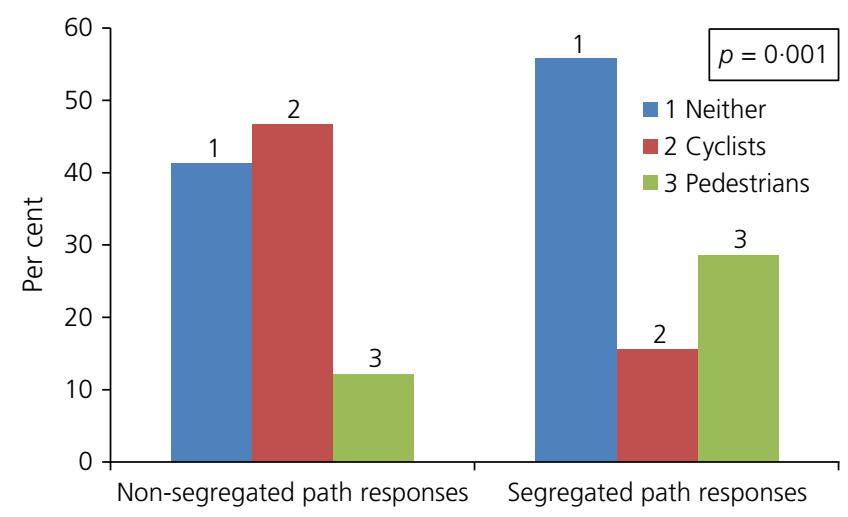

Figure 9. Who does have priority? (split by path type) 
transport corridor, although is now regarded by some as being a linear park.

The interview discussions show further detail on the attitudes towards segregation of shared-use paths. The respondents that were against segregation discussed the importance they placed on being able to share space harmoniously with others. For instance, one respondent (R7B) explains that 'what it [segregating path users] says about us as people is rather sad'. Her expectations from the path users as a group would be that everyone 'should be able to use it together without upsetting one another'. She highlighted a positive aspect of having a shared path

Well you get different sorts of people, people doing different things, people on it for different reasons, I suppose use a bit of a buzz word you know, for diversity (R7B)

Another respondent (R4C) also reflects on the diversity of a shared-use path compared with a segregated one. She admits that segregation might be 'slightly more efficient, but you wouldn't get as much enjoyment or variety'. She goes on to describe...

the unpredictability and variety of people that you get there... and it's the kind of secret worldliness of it as well, it's kind of like a story that unfolds of who you're going to come across and what have you (R4C)

There were also respondents who would prefer the path to be segregated. There were those that discussed their preference for segregation due to the differing speeds of cyclists and pedestrians

I think it's just that if you have someone going really fast you don't have to worry because they're on the other side, they're not going to impact you in any way (R9B)

From another point of view, there were those who would prefer segregation in order to be separated from pedestrians

Cyclists can be problematic, but the big problem is pedestrians, people just think it's a pavement... and that segregation would keep them on one side where they can behave in that way [not paying attention] if they want (R11B)

\section{Discussion: towards effective sharing of unsegregated paths}

The interview findings highlighted that the path users have not developed a set of norms or expectations of use that are distinctly associated with shared-use paths in general or the BBRP in particular. This is evident through the confusion and lack of clarity that appears to exist among the respondents in terms of individual behaviours and expectations of others on the path. This lack of clarity around the path and its use is having implications for path user relations and experiences.

For instance, there is confusion over which side of the path is considered best to walk/cycle on; some think that all users should keep left, the convention for all road vehicles in the UK, whereas others apply the Highway Code principles from motor vehicle roads to shared-use paths, arguing that pedestrians should stay to the right. The logic of this rule in the Highway Code presents the pedestrian as a vulnerable road user advised to face the oncoming threat of a fast motor vehicle and be ready to take evasive action. Application to a shared-use path also positions the pedestrian as a vulnerable, rather than equal, user. In practice, pedestrians could be observed following either convention (and also walking down the centre of the path).

In addition to reducing the practical efficiency of the infrastructure, which at peak times can experience congestion, the ambiguity also has a negative effect on how path users react to each other. For instance, one respondent's account highlights her reactions to another path user who was using the path 'incorrectly'

There was this guy and I could see him coming up on the right and everyone was going around him, he was not moving out of the way for anybody. So when I got up to him [cycling] I moved closely around him and didn't give him as much room as I could have to kind of prove a point you know, I moved around him as much as I needed to and then pulled right back in (R9B)

There are also differing interpretations of the path's name, and even these perceptions appeared to be linked to behaviour and expectations about others' behaviours. For instance, respondent 3B shows his cycling style and speed when using the path. It is apparent that his interpretation of the name is related to his style of cycling; 'I would definitely go faster but that's because it's more of a dedicated cycle path'. When describing the path at busy commuter times he says that 'at least half the people are going at a relative speed, you know $15 \mathrm{mph}$ or something and I think that's right for a cycle path'. The crucial point here is that the respondent's expectations of his relative speed as a cyclist on the path are related to the fact that he perceives it as a 'cycle path' rather than a shared-use path.

Another participant (R9B) uses the path for cycling and walking yet she interprets it as a 'cycle track'; this leads to her being frustrated by pedestrians

...you've got people who just take up loads of space and you're like 'come on, you know it's a cycle track', I'm ringing my bell and they're not moving and that does frustrate me (R9B) 
Additionally, during the interview discussions the respondents automatically referred to their expectations of the road/ pavement as a reference point when interpreting the shared-use path and its users. The road and pavement, as spaces of mobility, have well-established norms, learned behaviours and expectations; and thus the respondents refer to these spaces for confirmation of behaviour. For instance, one respondent (R6C) refers to the road rules in order to develop a reaction to a couple of cyclists on the path: 'if you're going to cycle two abreast you should cycle closer together...it's not responsible road use' (R6C).

There were also respondents who specifically referred to cyclists on the path as one would to motor traffic on the road. Respondent 14B describes the path as often having 'too much traffic' and then goes on to clarify by saying 'too many bikes' and thus specifically referring to cyclists as traffic. Even more specifically, the respondents discussed 'people' (pedestrians) and 'bikes' (cyclists) rather than pedestrians and cyclists, or people walking and people cycling. Such as this account: 'As I look around me yeah I know if there are other bikes and other people and so on' (R11B). This type of terminology was used both by cyclists and pedestrians. For instance, when one respondent (R2C) is discussing priority she talks about 'bikes dominating the path' and 'people who are walking...'

There's no doubt that the bikes dominate that path, I mean that's what I feel, I don't know what people who are walking feel, but there are more bikes, they are going faster (R2C)

\section{Conclusions and recommendations}

The empirical findings presented in this paper derive from user experiences on a specific shared-use route. Many aspects of the BBRP, such as its asphalt surface, and the mixture of cyclists and pedestrians are common to other walking and cycling spaces in urban areas. It is heavily used, as more shared-use paths are likely to become if active travel policies prove effective. However, it would also be beneficial to carry out further research at additional sites in order to gain an insight into alternative path and user characteristics.

The shared-use path design guidance recommends that the decision to segregate shared-use paths should be determined by the specific context of the path and certain design considerations (DfT, 2012a). However, this paper demonstrates that once path users' experiences and perceptions are introduced to these deliberations the decision becomes more complex for the designer. In particular, in the context of a width-constrained path, a key finding is that while pedestrians generally prefer segregation as they feel safer and more prioritised, cyclists favour non-segregation, as enabling them to make more efficient progress. A further pragmatic factor is that, in the UK at least, segregation is often achieved by painted markings which in many instances fade with time; and so the priority is no longer apparent, and it has sometimes been implemented where widths are insufficient. A width of $3 \mathrm{~m}$, as on the BBRP is clearly too narrow to allow for effective segregation, whereas $6 \mathrm{~m}$, as in Castle Park, is sufficient; the Dutch Design Manual for Bicycle Traffic (Groot, 2007) provides guidance on the minimum and ideal widths for each type of path.

Whether shared-use paths are segregated or unsegregated, this study has emphasised the importance of a local user culture for their efficient and enjoyable use. Here, it is suggested that locally influenced codes of conduct for shared-path use can fill a regulatory gap which is otherwise being filled by the general purpose Highway Code (DfT, 2015); which is largely designed to protect vulnerable road users from dominant motor vehicles, rather than promoting genuine sharing of space. Even the choice of route name can influence this culture, with the term 'cycle path' implying cyclist priority over pedestrians and 'railway path' perhaps emphasising utility use over leisure use. Again, sometimes establishing the priority of one group may be appropriate, and the same priority may not necessarily apply to a whole route.

However, once the design approach is decided, a code of conduct should seek to reduce the potential conflict between users through promotion of a common perspective and understanding of the path and the community it serves. To this end, it is recommended that the terminology used in policy, guidance, media and any other influencing documents should be carefully considered in order to promote shared-use paths and path users as distinct from highways and highway users.

Specifically regarding the reported behaviour of pedestrians on unsegregated paths, and in relation to the factor which caused most confusion among path users, it is recommended that the normal guidance for shared-use paths should be to 'keep left' (in the UK or right where it is the rule on the road), for the following reasons

- 'Keep left' can be communicated in a more simple and concise manner to all users, in comparison with seeking to assign different instructions/sides to different modes.

- It emphasises all users sharing on an equal basis, and that the infrastructure is not a highway.

- In constrained spaces, the flow will tend to be more efficient and less frustrating for users; as the interactions will be more often in terms of differential speed, not direction of movement.

Thus, if walking and cycling levels are to increase in the future, it is important to consider the experiential factors from 
the users' perspectives. This paper has aimed to enhance the understanding of shared-use path experiences to contribute to current and future path design and management.

\section{Acknowledgements}

The authors acknowledge the research participants who gave their time to take part in this project and the University of the West of England for having funded the $\mathrm{PhD}$ research from which this paper has derived.

\section{REFERENCES}

Atkins (2012) Shared Use Operational Review. Atkins, London, UK. See http://www.gov.uk/government/ uploads/system/uploads/attachment_data/file/9181/ atkins-shared-use-operational-review.pdf (accessed 08/09/2016)

Beecham R and Wood J (2013) Exploring gendered cycling behaviours within a large-scale behavioural data-set. Transportation Planning and Technology 37(1): 1-15.

Braun V and Clark V (2006) Using thematic analysis in psychology. Qualitative Research in Psychology 3(2): 77-101.

CC (Cardiff Council) (2010) Hailey Park Code of Conduct. Cardiff Council, Cardiff, UK. See http://www. friendsofhaileypark.org.uk/uploads/1/9/5/1/1951271/ hailey_park_code_of_conduct_english.pdf (accessed 19/02/2015).

CED (Cycling Embassy of Denmark) (2012) Collection of Cycle Concepts. Cycling Embassy of Denmark, Copenhagen, Denmark. See http://www.cycling-embassy.dk/2012 (accessed 03/02/2015).

Davies A (2012) Can cyclists and pedestrians share public space? The Urbanist [blog]. Crikey, Melbourne, Australia. See http://www.blogs.crikey.com.au/theurbanist/ (accessed 10/07/2015).

DfT (Department for Transport) (2004) Adjacent and Shared use Facilities for Pedestrians and Cyclists, Local Transport Note 2/04. Annex D: Code of Conduct Notice for Cyclists. Department for Transport, London, UK. See http://www.dft.gov.uk (accessed 03/02/2015).

Dft (2012a) Shared use Routes for Pedestrians and Cyclists, Local Transport Note 1/12. Department for Transport, London, UK. See http://www.dft.gov.uk (accessed 03/02/2015).

Dft (2012b) National Travel Survey - Where People Cycle. Department for Transport, London, UK. See http://www. gov.uk/government/statistical-data-sets/nts03-modalcomparisons (accessed 03/02/2015).

Dft (2014) National Travel Survey: Statistical Data Set Walking and Cycling (TSGB11). Department for
Transport, London, UK. See http://www.gov.uk/ government/statistical-data-sets/walking-and-cycling-tsgb1 1 (accessed 08/09/2016).

DfT (2015) The Highway Code. Department for Transport, London, UK. See http://www.gov.uk/highway-code (accessed 03/02/2015).

Furth PG (2012) Bicycling infrastructure for mass cycling: a transatlantic comparison. In City Cycling (Pucher $\mathbf{J}$ and Buehler R (eds)). MIT Press, Cambridge, MA, USA, pp. 105-140.

Gallagher R and Parkin J (2014) Planning for Cycling. CIHT, London, UK.

Golbuff L and Aldred R (2011) Cycling Policy in the UK: $A$ Historical and Thematic Overview. University of East London, London, UK.

Groot R (2007) Design Manual for Bicycle Traffic. CROW, Utrecht, the Netherlands.

Hembrow D (2014) Shared Use Paths. A View from the Cycle Path [blog]. Blogger, Assen, the Netherlands. See http://aviewfromthecyclepath.com/2014/11/ (accessed 07/05/2015).

Lakin N (2015) Cyclists vs Pedestrians. Lancaster Guardian, 12 June. See http://www.lancasterguardian.co.uk/news (accessed 10/07/2015).

Melia S (2015) Urban Transport without the Hot Air. UIT Cambridge, Cambridge, UK.

ONS (Office for National Statistics) (2014) 2011 Census Analysis - Cycling to Work. Office for National Statistics, Newport, UK. See http://www.ons.gov.uk/ons/dcp171776_ 357613.pdf (accessed 09/06/2014).

Pooley C, Tight M, Jones Tet al. (2011) Understanding Walking and Cycling. Lancaster University, Lancaster, UK. See http://www.its.leeds.ac.uk/fileadmin/user_upload/ UWCReportSept2011.pdf (accessed 03/02/2015).

Road Traffic Act 1991. The Stationery Office, London, UK.

Sustrans (2013) Advice on Using Shared-use Paths. Sustrans, Bristol, UK. See http://www.sustrans.org.uk/change-yourtravel/get-cycling/cycling-code-conduct-shared-use-paths (accessed 03/02/2015).

Sustrans (2014a) Design Manual Chapter 5; Traffic Free Routes - Conceptual Design (Draft). Sustrans, Bristol, UK. See http://www.sustrans.org.uk/our-services/ infrastructure/route-design-resources/documentsand-drawings/key-reference-documents (accessed 03/02/2015).

Sustrans (2014b) Millions of People on the Move, Usage and Benefits of the National Cycle Network in 2013. Sustrans, Bristol, UK. See http://www.sustrans.org. uk/sites/default/files/file_content_type/sustrans-ncn-report2013.pdf (accessed 03/02/2015).

Sustrans (2014c) Two Tunnels Greenway - Code of Conduct. Sustrans, Bristol, UK. See http://www.twotunnels.org. uk/code-of-conduct.html (accessed 19/02/2015). 
Sustrans (2015a) About the National Cycle Network. Sustrans, Bristol, UK. See http://www.sustrans.org.uk/ncn/map/ national-cycle-network/about-network (accessed 03/02/2015). Sustrans (2015b) Sustrans: Connect2 and Greenways Design Guide. Sustrans, Bristol, UK. See http://www.sustrans.org. uk/our-services/infrastructure/route-design-resources/ documents-and-drawings/key-reference-documents- 0 (accessed 03/02/2015).

TfL (Transport for London) (2014) London Cycling Design Standards. Transport for London, London, UK. See http://www.tfl.gov.uk/corporate/publications-andreports/cycling (accessed 19/2/2015).

\section{HOW CAN YOU CONTRIBUTE?}

To discuss this paper, please email up to 500 words to the editor at journals@ice.org.uk. Your contribution will be forwarded to the author(s) for a reply and, if considered appropriate by the editorial board, it will be published as discussion in a future issue of the journal.

Proceedings journals rely entirely on contributions from the civil engineering profession (and allied disciplines). Information about how to submit your paper online is available at www.icevirtuallibrary.com/page/authors, where you will also find detailed author guidelines. 